\title{
The perspective of optometry students of the Phelophepa train regarding its role in developing experiential skills
}

\author{
R Hansraj* \\ Discipline of Optometry, Faculty of Health Science, University of Kwazulu-Natal Private Bag \\ X54001, Durban, 4000 South Africa \\ <hansrajr@ukzn.ac.za>
}

Received 25 November 2008; revised version accepted 22 May 2009

\begin{abstract}
Purpose: The optometry degree programme in South Africa currently includes a combination of both theoretical and clinical modules. The optometric skills required by graduates are often achieved by students' involvement in clinical training at both in-house clinics, as well as external clinics. One of the external clinic sites for all institutions in South Africa currently offering the Optometry degree is the Phelophepa Health Care train. This study set out to investigate, from a student's perspective, the effectiveness of experiential learning at this clinical site.

Setting: The study was carried out aboard the Phelophepa Health Care train.

Method: A questionnaire survey was completed by a saturated sample of 177 optometry students having completed at least a two week clinical rotation aboard Phelophepa. The sample comprised students from all four optometry programmes in South Africa, as well as, exchange optometry students from the University of New South Wales and Melbourne University. The questionnaire was divided into five sections that dealt with demographics, equipment and facilities, profile of refractive and pathology cases encountered, additional skills and general perceptions. The self-administered questionnaire was in English and Afrikaans, as these are the two language mediums in which optometric education,
\end{abstract}

in South Africa, is currently delivered.

Results: A response rate of 57\% was obtained. The equipment and facilities aboard Phelophepa were found to be adequate. Just over half of all the respondents had consulted with over 50 patients on Phelophepa during their two week rotation. Communication was not reported as being a barrier to consulting with patients on Phelophepa. Respondents reported the clinical cases as being mainly interesting and 'good learning' cases. The majority of respondents (71\%) felt that the general clinical skills they obtained on Phelophepa were better than those developed in their institutional clinics. Not all refractions and ophthalmoscopy on patients are supervised aboard Phelophepa. There appears to be a need for the delivery of specialized optometry skills like binocular vision, paediatric vision, low vision and diagnostic techniques on Phelophepa. All the respondents agreed that Phelophepa was a useful learning site, and 99\% agreed that optometry departments should continue using it as an external clinic site.

Conclusion: Despite certain shortcomings, undergraduate students perceive Phelophepa to be a useful learning experience that optometry schools in South Africa should continue to utilize.

Key words: experiential learning, undergraduate education, refraction, ophthalmoscopy 


\section{Introduction}

The Bachelor of Optometry degree is currently offered at four institutions in South Africa namely University of Kwazulu-Natal (UKZN), University of Limpopo (UL), University of Johannesburg (UJ) and Free State University. The curriculum at all institutions encompasses theoretical, practical and clinical modules. Clinical training in the clinical modules is achieved in most part by students consulting with patients and this has proven to be an invaluable source of experience and knowledge. The initial design of these clinical modules was influenced greatly by a report submitted to the South African Optometric Association by a commission of enquiry ${ }^{1}$ into optometric education in South Africa in 1980. This report was of vital importance as the three departments of optometry operating at that time were in their fledging states ${ }^{2}$. One of the statements highlighted in the conclusion of that report was that: "for maximum educational value, institutionally supervised optometric training clinics should attract a significant share of patients, representative of those that students can expect to see later in practice and a significant share of patients with highly anomalous and pathological conditions" 1 .

According to the Council of Higher Education's (CHE) - criteria for institutional audits, June 2004, service learning is defined as: "applied learning which is directed at specific community needs and is integrated into an academic programme and curriculum"3. Service learning has also been identified by Kearney ${ }^{4}$ as a means in any curriculum to effect relevant learning. In South Africa clinical training and community optometry especially in the modules concentrating on general refraction skills are often done at both internal and external clinic sites to allow for exposure of the optometry student to patients and community optometry. Mullen ${ }^{5}$ asserted that future planning of clinical education should consider the need for greater diversity of clinical experiences and thus community-based training sites will need to replace campus-based clinics (http://www.charlesmullen.com/trends.html). For this reason, clinical sites external to the discipline now form an integral part of the clinical training of optometry students. Furthermore, the external clinic sites form the core of the outreach services offered by the disciplines and part of the service learning. These community optometric services, which become the external clinic sites, are thus an important aspect of vision health education programmes $^{6,7}$.

One such external training site in South Africa is Phelophepa. Phelophepa, which means good health, was conceived as Transnet's Primary Health Care Train in 1993. In its first year the train visited over thirty different stations ${ }^{8}$ and provided health care for over 26000 people. The initial goal in creating such a mobile service was to provide eye care services to rural communities that have little or no access to primary health care services, and to allow an opportunity for 'hands-on' experience by optometry undergraduate students (http://www. African Business Journal Trade, Investment \& Tender Information for Africa. $\mathrm{htm})$. This commitment to contribute to undergraduate clinical training was reflected in one its mission statements: "To provide students in the health care field with an opportunity to gain valuable practical experience" 9. Phelophepa started off as a thirteen coach carrier which included an eye-clinic, an educlinic and a pharmacy clinic, and has today grown to a 16-coach carrier, now boasting a health clinic, a pharmacy, a dental clinic, and also psychology, optometry and a catering department - all staffed by students from various training institutions ${ }^{10}$ (http://www. African Business Journal - Trade, Investment \& Tender Information for Africa.htm). In addition, staff and students engage in outreach programmes in the form of vision screening co-ordinated from within the train in the different areas visited.

Phelophepa, since its inception has thus become an integral part of the clinical training programme at all institutions, however, a literature search revealed only one unpublished study relating to the delivery of eye care on this health care train. The study by Arbee $e a^{10}$ in 1994 evaluated the quality of eye care provided on Phelophepa. This study found that the facilities and equipment available on the train were adequate to meet the requirements of a quality eye care programme ${ }^{10}$. However, supervision of the final prescription, dispensing of spectacles and ophthalmological cases was found to be minimal. No study has been done since then and furthermore no study has attempted to investigate whether Phelophepa is an effective site for the undergraduate optometry clinical programme. The aim of this study therefore was to 
evaluate from a student's perspective the effectiveness of experiential learning aboard the Phelophepa Health Care train in developing optometry skills at undergraduate level.

\section{Methodology \\ Study design and sampling}

A quantitative and qualitative research design was employed in the form of a questionnaire survey* developed by the researcher.

The study population comprised of all optometry students at the University of Kwazulu-Natal, University of Johannesburg, University of Limpopo and Free State University, as well as, a few exchange students from the Department of Optometry at the University of Melbourne and New South Wales who had completed at least a two week clinical rotation on Phelophepa in 2008. As the number of final year optometry students collectively throughout South Africa is limited the study population also formed the study sample and a saturated sample was used. Hence the questionnaire was distributed to all 203 students that had completed the rotation in 2008.

\section{Materials and procedure}

A questionnaire* comprising both open and closedended questions was the data gathering instrument. The questionnaire was divided into the following broad sections:
i. Demographics
ii. Equipment and Facilities
iii. Profile of Refractive and Pathology cases
iv. Additional skills
v. General

The questionnaire was administered either in English or Afrikaans, as these are the two language mediums in which optometric education, in South Africa, is currently delivered. On receipt of ethical clearance from the Faculty Research Committee of UKZN questionnaires were couriered to Phelophepa. The resident optometrist distributed the questionnaires to the students once they had completed their rotation. The questionnaires were then collected and returned to the author.

\section{Results and Discussion}

\section{Demographics}

A response rate of $57 \%$ was achieved. The respondents $(n=115)$ were between the ages of 20 and 37 years (mean age $=23$ ). This study sample thus represented the new and younger generation of optometrists to emerge into the field. The male:female ratio was approximately $1: 2$ and this ratio was expected as currently the optometry programmes have more female students than males. The respondents comprised of students from all four optometry departments in South Africa and six respondents who were exchange students from Australia. The majority of South African students were from the University of Limpopo (33\%). This relates to the fact that the department of optometry at the University of Limpopo had the largest student population during 2008. The majority of the respondents $(89 \%)$ were in their final year of study, with the remaining (11\%) currently in their third year of study. The respondents had spent an average of two weeks on Phelophepa (mean $=13$ days), with the majority of respondents (88\%) having completed one rotation only.

\section{Equipment and Facilities}

The clinical environment or set-up with regards to available equipment and working space can impact on the type of eye care that can be delivered. Figure 1 depicts the respondents' perception of the clinical facilities aboard Phelophepa.

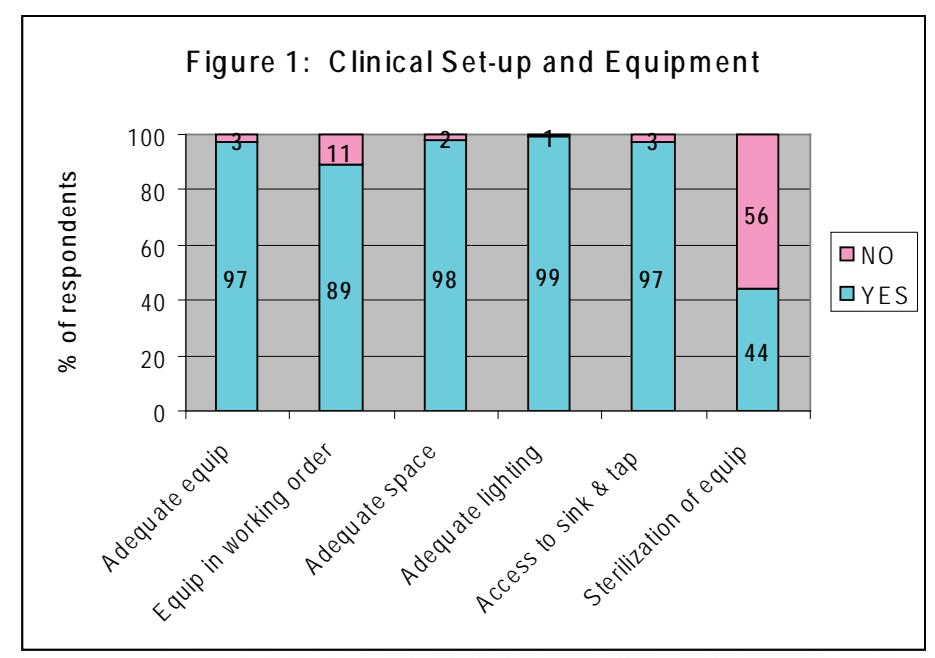

* Should you require a copy, the questionnaire is available directly from the author who can be contacted via email. 
Overall, the clinical set-up with respect to working equipment and working space was perceived as being adequate to conduct general refractions. This was also reflected in the study by Arbee et $a l^{10}$ who found that Phelophepa complied fully with utilisation of accepted and validated methods of providing eye care, and correct utilisation of technological resources. It was heartening to note that the majority of respondents $(97 \%)$ indicated that they had access to a sink and tap, which implies that they could wash their hands both before and after examining each patient. This is particularly important as Lakkis et al ${ }^{11}$ asserted that hand-washing is the most important measure in preventing the spread of infection in a health care setting. Of concern, however, was the fact that facilities for sterilization of equipment was not always available. It is the responsibility of the practitioner to take measures to decrease the risk of transmission of infections ${ }^{11}$. This may involve a simple wiping of the phoropter forehead rest, and slit lamp chin rest with alcohol swabs. Proper hygiene of this sort is of particular importance considering the number of patients that are seen on Phelophepa on a daily basis, as well as some of the contagious pathological conditions such as conjunctivitis that could be encountered.

\section{Profile of clinical case exposure aboard Phelophepa}

The majority of respondents (50\%) had seen more than 10 patients per day, which explains also why the majority of respondents (50\%) had consulted with more than 50 patients in the entire time spent on Phelophepa. This was a considerable number of patients that undergraduate optometry students had been exposed to considering that at the University of Kwazulu-Natal for example, the maximum number of patients that a student would be exposed to in a two week period would be in the region of 14. The popularity of the eye clinic has been reflected in the 1999 statistics, as being the most frequented facility aboard Phelophepa, with $43 \%$ of the total number of visits to the train being to the eye clinic and with the eye clinic contributing $76 \%$ of the total income received on the train $^{9}$. A similar trend was still observed six years later ${ }^{12}$, in 2005.

The majority of the respondents (73\%) considered this total number of patients seen as being adequate with only $16 \%$ judging it as too many. It would have been expected that based on the large number of patients seen on a daily basis, the time allocation per patient may not have been adequate. However, the majority of the respondents (95\%) believed the time allocation to be adequate.

Effective communication is imperative to ensure the safety and quality of health care provided ${ }^{13,14}$. South Africa currently has eleven official languages. As Phelophepa travels throughout South Africa, often students are exposed to patients who speak a language with which they are unfamiliar. In order to perform a proper eye test and vision assessment, however, it is imperative that there is good communication between the examiner and the patient. But language differences were not found to be a major barrier to the delivery of eye care aboard Phelophepa, as 65\% of the respondents agreed that they were able to communicate adequately with the patients. This finding may be attributed to the fact that Phelophepa employs translators who assist the clinicians in their consultation with the patients with $96 \%$ of respondents indicating that there were an adequate number of translators available to assist during the refractions. This was encouraging to note as the study by Arbee et $a l^{10}$ had cited communication due to language barriers as one of the factors contributing to the quality of eye care aboard Phelophepa, which at that time, was judged as being of a relatively compromised standard. Using the chi-square test of Pearson, no significant correlation was found between the institution that the respondent belonged to, which may be reflective of the area of South Africa that they are native to, and their ability to communicate with the patients $\left(\chi^{2}=18.237, p=0.109\right)$. A trend was noted though that the students from the University of Limpopo had less difficulty communicating with patients than those from the other institutions. No significant correlation was also found between the area visited and communication ability $\left(\chi^{2}=21.835, p=589\right)$.

Supervision protocols were found to be slightly different to that of the internal clinics at the optometry departments. This was reflected in the response by $17 \%$ of the respondents that the refraction was not checked on every patient, and 31\% who indicated that ophthalmoscopy was not checked on every patient. Reasons given as to why this was the case included the following:

i. The supervisor was confident in the student's 
ability.

ii. The visual acuities were satisfactory.

iii. There was no time.

iv. Only cases where pathology was detected were checked.

v. Ophthalmoscopy was only performed if there was no improvement in the visual acuity or with pinhole.

vi. Only if the student was uncertain.

The refraction and ophthalmoscopy are checked routinely by supervisors at the internal clinics of the departments, irrespective of the other findings. This is of particular importance to ensure that the patient receives a comprehensive and accurate assessment, as well as, to assist the student in the learning process by pointing out areas that may have been incorrect. Students' areas of weakness in their clinical skills can only be detected with adequate supervision. The eye clinic aboard Phelophepa, at any one time in the year, is staffed with two qualified optometrists and an optical dispenser, who supervise the clinical work of the students. Therefore, factors that may have contributed to not all patients being supervised include the limited number of supervisors aboard Phelophepa, and the large number of patients seen on a daily basis. Arbee et $\mathrm{al}^{10}$ reported that the care provided aboard Phelophepa complied partially with being able to provide optimal vision and ocular health care, especially with regards to the commitment to early diagnosis, prevention and promotion of eye health. Compelling legal reasons also require that each patient encounter at the external clinic sites of the New England College of Optometry, are supervised by faculty personnel ${ }^{17}$. Therefore, in the interests of the patients and learning, supervision aboard Phelophepa perhaps needs to be addressed. This is also particularly important as often the eye test received on Phelophepa for many South Africans is the only one they will receive in years and hence its accuracy must be ensured.

Respondents were required to rate both the refractive and pathology cases that they encountered (see Figure 2).

The majority of both the refractive and pathology cases were rated as being both "good learning cases" and "interesting". Very few were regarded as being routine. In the study conducted by Arbee et $a l^{10}$, $26 \%$ of subjects saw the development of their clinical skills as being a greater benefit to them than that of meeting the needs of the South African population. Students thus have an expectation of primarily further developing their clinical skills during their rotation on Phelophepa. Phelophepa is a unique clinical training site as it exposes the student to communities and ocular conditions that they are unlikely to encounter either at their discipline based clinics or external clinic sites in close proximity with their institutions, as many of the sites that they visit during their rotation on Phelophepa are mainly in rural areas and outside of their native province. The need for as much variety as possible in clinical experience was emphasised as early as $1981 .{ }^{15}$ This may be particularly important in terms of exposure to the range of ocular pathology seen in South Africa. Exposure to ocular pathology

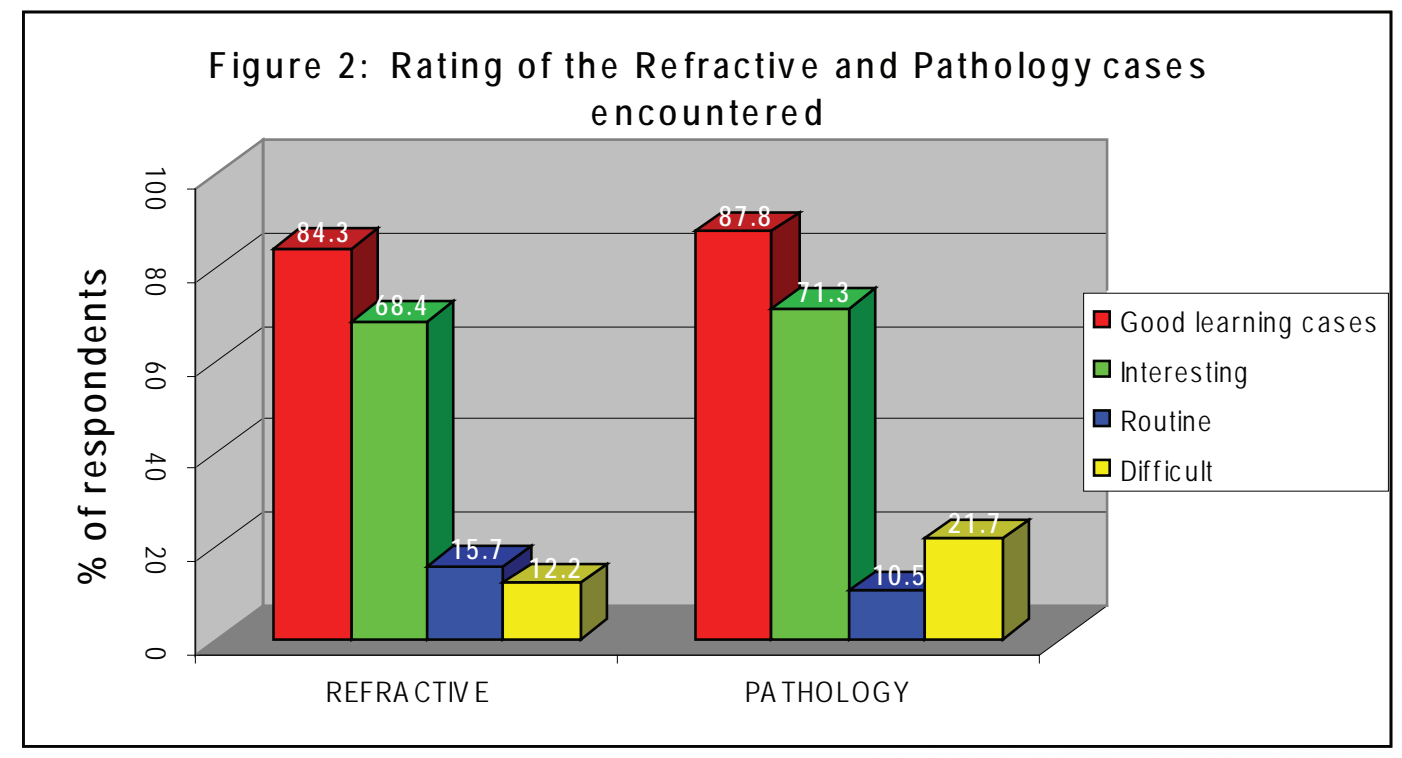


was quoted as one the areas that needed improvement in the optometry programmes by optometry graduates of the ex Rand Afrikaans University in a survey in 1996. ${ }^{16}$ It was therefore heartening to observe the trend in Figure 3.

Figure 3 shows that a perceived improvement in all clinical skills following their rotation on Phelo-

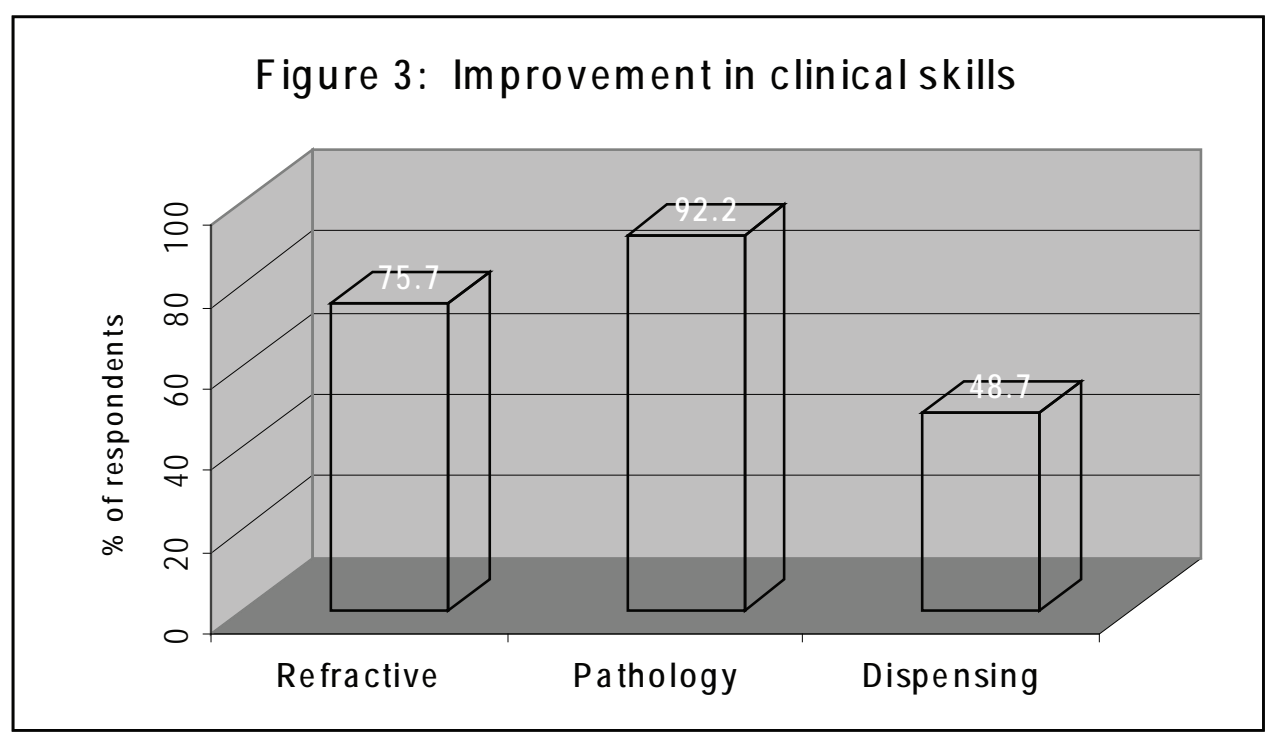

phepa was reported by the respondents. The greatest improvement, however, was noted in the diagnosis of pathology (92\%). Even though as "student optometrists", an overwhelming majority of respondents (98\%) felt that they were adequately prepared to deliver eye care aboard Phelophepa, the majority of respondents (71\%) still rated the skills obtained aboard Phelophepa as being "better" than that obtained in their respective department/discipline eye clinic.

The delivery of specialized optometric care was found to be lacking aboard Phelophepa even though there appeared to be a need based on the patient's needs as perceived by the respondents (see Figure 4).

With the exception of contact lenses, many of the respondents had encountered patients that required

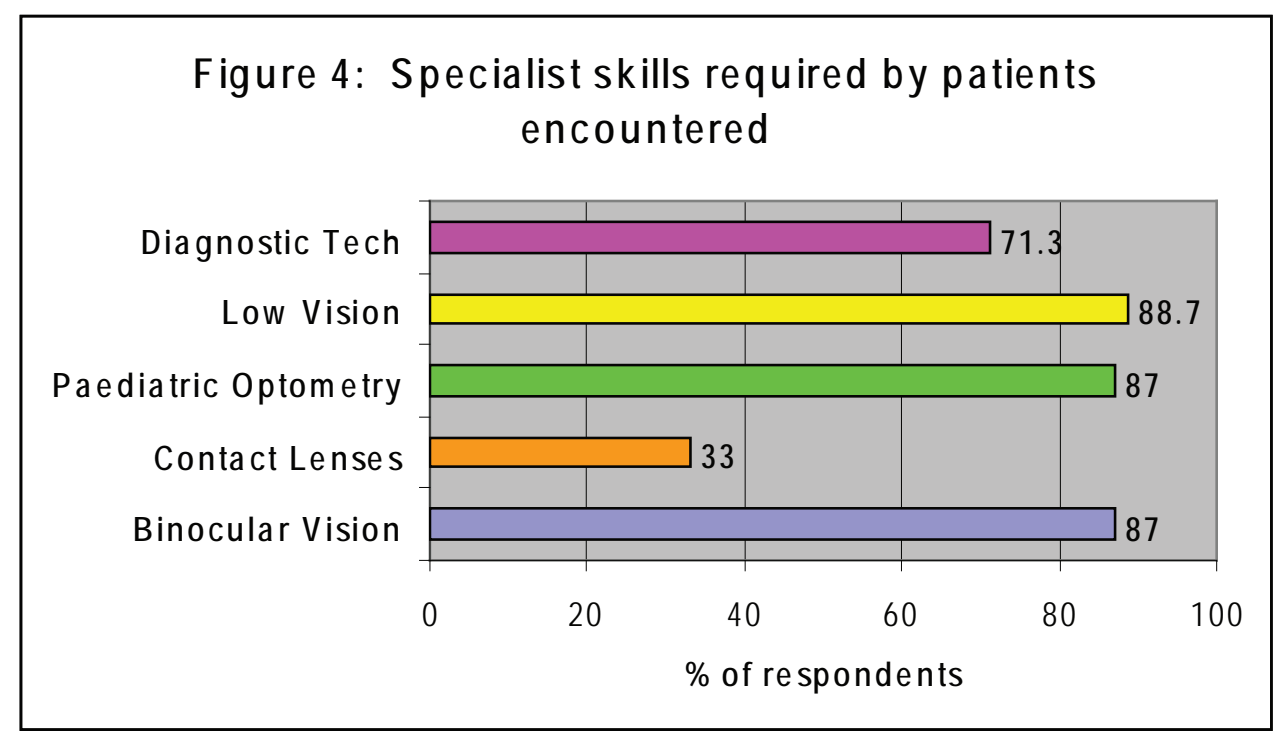

binocular vision, paediatric optometry, low vision or diagnostic techniques namely contact tonometry and a dilated fundus examination, to be performed on them. Many (56\%) of the respondents believed that it would not be possible to provide these special- ist skills on Phelophepa. Time (44\%), equipment (48\%) and the need for follow-up visits (57\%) were judged by the respondents as being the main barriers to providing specialist skills aboard Phelophepa. 


\section{Additional Skills}

Multidisciplinary settings at clinical training sites are ideal as they allow for learning, the opportunity to consolidate management strategies and result in an improved quality of care. This subsequently benefits both the patient and the provider ${ }^{17}$. Phelophepa is also staffed by dentistry, pharmacy and psychology and hence provides a multi-disciplinary setting. The majority of the respondents interacted with all three of the above-mentioned disciplines during their clinical rotation on Phelophepa. Following their interaction with other disciplines, most agreed that such a setting is beneficial to both the patient (98\%) and the health care professionals (94\%). This type of setting is currently not possible at the internal clinics within the optometry departments. The following reasons were given as to the benefits of such a setting: i. Allows the patient easy access to health care.

ii. Provides for a holistic approach in the care of the patient.

iii. Allows for better patient management.

iv. Provides an opportunity for health care professionals to learn from each other.

Avery $^{18}$ asserted that tertiary institutions aim to produce life long learners who will grow in their careers as well as become productive citizens. Hence educational modules have specific learning outcomes which include knowledge, skills and attitude. In addition to the clinical skills obtained the respondents felt that they had benefited in other areas as well during the course of their rotation on Phelophepa which can be classified as critical cross-field outcomes (see Figure 5).

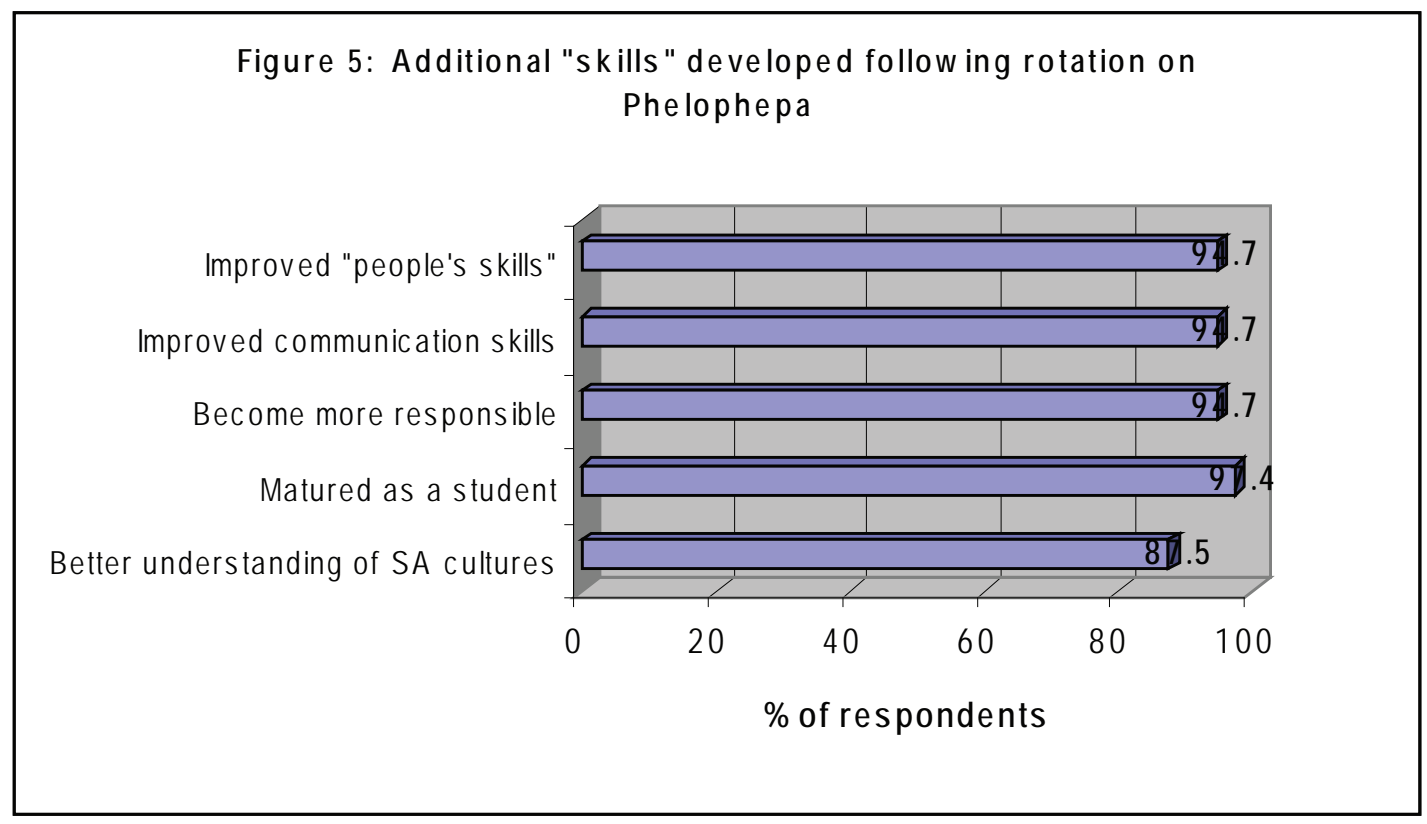

Phelophepa thus appears to be an effective external training site for optometry schools in South Africa. Sheni ${ }^{2}$ suggested the curriculum and training of optometrists in Africa should be aimed at producing optometrists who can perform general and ocular first aid, community optometry and understand public health, amongst others. He therefore emphasised that the curricula of optometry schools need to be designed to "meet the needs of their communities and the growing demands of optometry"2, which would require that students be trained within the community during their formal university courses. This senti- ment was reiterated by Mullen $^{5}$ that in future there will be more collaboration with community health care programs and an increased awareness of public health needs (http://www.charlesmullen.com/trends. html). Similar findings were reported by Satishkumar et $a l^{19}$ that clinical exposure sensitises the student more to the patient's problems and needs. Similarly, the New England College of Optometry collaborates with community health centres to allow their students exposure to large number of patients from diverse backgrounds, with complex health care, eye care and social needs ${ }^{7}$. This type of appreciation of the skills 
developed aboard Phelophepa has existed since the origination of this project. The Transnet Foundation Health Portfolio regional report for the period 1 January to 5 May 2006 carried a quotation from a student that: "I have never learned so much in my life as in these two weeks - my people skills, pathology knowledge, testing ability and my whole approach has improved tremendously”.

\section{General}

All the respondents agreed that Phelophepa was a useful learning site, and 99\% agreed that optometry schools in South Africa should continue sending students for clinical skills training aboard Phelophepa. Some suggestions from the respondents for future improvement of Phelophepa included:

i. The need for more such health care trains to improve access to the people, with the aid of government funding.

ii. In terms of dispensing, a wider range of pow ers to be given, and CR39 lenses to be used instead of glass.

iii. The need for more supervisors.

iv. The facilitation of discussion sessions at the end of the day for students to present interest ing learning cases.

v. The inclusion of ophthalmology in the eye clinic.

\section{Conclusion}

The practice of optometry is both theoretical and clinical hence it is of vital importance that the optometry graduate is competent not only in the theoretical aspects but also has the relevant clinical skills to perform comprehensive and superior visual examinations. This outcome is heavily dependent on both the academic and clinical training during the undergraduate programme which tends to be largely patientbased. Undergraduate optometry students, at all four optometry training programmes in South Africa consult with patients primarily at their internal eye clinics. However, to allow the student an opportunity to examine a sufficient number of patients, thereby ensuring exposure to a variety of optometric patients and clinical settings, students are also required to attend optometry clinics external to the university. Phelo- phepa has served as an external clinic site for all institutions for the past fifteen years exposing students to a wide variety of clinical cases. Since the evaluation study by Arbee et $a l^{10}$ there has been improvement in the delivery of eye care and expansion of Phelophepa. However, there are certain problematic areas that still exist. It is recommended that clinical hygiene such as hand-washing be done with alcohol based hand antiseptics or chlorhexidine as soap is ineffective against microbial activity ${ }^{11}$. Sterile techniques are of utmost importance in any health care field and in eye care delivery aboard Phelophepa can involve simple things like wiping of the chin rest, and phoropter forehead rest with alcohol swaps in between patients. The use of translators has definitely facilitated the communication with the patients on Phelophepa. However, it is also important to train the translators to ensure that optometric terms and pathological conditions are relayed correctly to the patients. There is a definite need for more supervisors in the Phelophepa train clinic considering the large number of patients who use this community service. This will ensure that all refractions and ophthalmoscopy are confirmed which will benefit both the patient and the student. There appears to be a need to be able to provide specialist optometry skills for binocular vision, paediatric vision and low vision. Furthermore, considering the gradually expanding scope of optometry with regards to diagnostic techniques and especially therapeutics, the performance of diagnostic techniques such as gonioscopy or dilated fundus examinations may negate the need for the patient to have to travel to the hospital eye clinic which in many instances might be far away. Overall, however, Phelophepa is judged by its harshest critics, the undergraduate students, as being an excellent and most useful external clinic site which provides more than just clinical knowledge and skills.

\section{Acknowledgements:}

Sincere gratitude is expressed to Transnet, especially Dr Giles and Dr Coetzee for assistance with the distribution and collation of the answered questionnaires. 


\section{References}

1. Hofstetter HW. Report to the president of the South African Optometric Association. S Afr Optom 198039 63-99.

2. Sheni DD. The future of optometry in Africa. S Afr Optom 199855 16-18.

3. Council of Higher Education's (CHE) - criteria for institutional audits, June 2004.

4. Kearney KR. A service-learning course for first-year pharmacy students. Am J Pharm Educ 20087286.

5. Mullen (2005). (http://www.charlesmullen.com/trends.html) accessed July 2007.

6. Shaik, R. Public Health Optometry-A Theoretical Framework. S Afr Optom 199453 4-9.

7. Wilson R, Sharda V. History of community health center affiliations with The New England College of Optometry. JAOA 200879 594-602.

8. Bulbulia A and Ferreira JT. The Phelophepa Mobile Heath Care Study: Prevalence of Primary Open-Angle Glaucoma. S Afr Optom 199756 55-60.

9. Pretorius CA. Transnet Phelophepa Health Care Train Report: Mpumalanga, 24 May to 9 August 1999.

10. Arbee M, Jogessar Y, Dowlath S. An evaluation of Phelophepa to assess the quality of eye care provided. Unpublished final year research project in the Discipline of Optometry, University of Durban-Westville, South Africa, 1994.

11. Lakkis C, Lian KY, Napper G, Kiely. Infection control guidelines for optometrists 2007. Clin Exp Optom 200790 434-444.

12. Giles TB, Rapoo E, Hlongoane S. Transnet Foundation Health Portfolio, Kwazulu-Natal, Regional Report: 30 May to 29 July 2005 - Report from the Eye Clinic.

13. Schyve PM. Language Differences as a Barrier to Quality and Safety in Health Care: The Joint Commission Perspective. Gen Intern Med 200722 360-361.

14. Ruan J, Lambert VA. Differences in perceived communication barriers among nurses and elderly patients in China. Nurs Health Sc 200810 110-116.

15. Murphy HL. Academic leaders look at the Optometry profession: Faculty opinions from the University of Indiana. $S$ Afr Optom 198140 203-207.

16. Fine L. Trends in demographics of Optometry graduates of Rand Afrikaans University. S Afr Optom 199655 6-11.

17. Wilson RJ, Hoffman DJ. Optometry in the multidisciplinary health care setting. Optom Vis Sci 198966 859-863.

18. Avery EF. Assessing student learning outcomes for information literacy instruction in academic institutions. Chicago : Association of College and Research Libraries, 2003.

19. Satishkumar S, Thomas N, Tharion E, Neelakantan N, Vyas R. Attitude of medical students towards Early Clinical Exposure in learning endocrine physiology. BMC Medical Education 2007730. 